\title{
Polycythaemia Vera with Abdominal Pain - An Unusual Association
}

\author{
BINOY KRISHNA TARAFDER, ${ }^{1}$ MOHAMMAD ASHIK IMRAN KHAN, ${ }^{2}$ MRINMAY KUMAR PODDAR, ${ }^{2}$ \\ ESTAKUR RAHMAN², MD. AMIRUZZAMAN ${ }^{3}$, MD. TITU MIAH ${ }^{4}$
}

\begin{abstract}
:
Polycythaemia vera is difficult disease to diagnose when it has an atypical presentation. Here we present a case where a middle aged man who presented to us with abdominal pain and recurrent peptic ulceration and was later diagnosed as a case of polycythaemia vera. To best of our knowledge this is the first report of such association from Bangladesh.
\end{abstract}

Keyword: Polycythaemia, vera, Abdominal pain, Peptic ulcer, Bangladesh

\section{Introduction:}

Abdominal pain is a common complaint presenting to primary care physicians, and accounts for $4-8 \%$ of all adult visits to a hospital emergency department. ${ }^{1,2}$ While approaching a patient with abdominal pain, one needs to be cautious as many causes can be missed if not kept in mind. The above statement is more true when one is working in a setting where reliance is mostly on clinical findings. Polycythaemia vera is a condition characterized as a panhyperplastic, malignant marrow disorder. The most prominent feature is the rise in red cell mass, often accompanied by rises in white blood cell and platelet counts. Leukaemic conversion occurs in $1-3 \%$ and the median survival with treatment is 13 years. ${ }^{3}$ We encountered a patient with upper abdominal pain, who had undergone repeated endoscopy for abdominal pain but was ultimately diagnosed with policythaemia vera.

\section{Case Report:}

A 50 year old married gentleman presented to our OPD with upper abdominal pain for 2 years. Pain was burning in

1. Junior Consultant, Medicine, 250 Bed Hospital, Sadar, Gopalgonj.

2. Medical Officer, Medicine, 250 Bed Hospital, Sadar, Gopalgonj.

3. Resident Physician, Sir Salimullah Medical College \& Mitford Hospital, Dhaka.

4. Associate Professor, Dhaka Medical College Hospital, Dhaka

Correspondence : Dr. Binoy Krishna Tarafder, Junior Consultant, Medicine, 250 Bed Hospital, Sadar, Gopalgonj. nature, episodic, related with food but no specific pattern, subsided by taking antiulcerant drugs . But over the last 3 months pain was almost on a daily basis, not adequately responding to antiulcerant drugs .Pain was not associated with fever or weight loss. He gave no history of hematemesis, malena or vomiting, chronic cough or respiratory distress. He was non alcoholic but smoker and smoked about 5 pack years. On query, gave history of generalized itching for last 3 yrs. His examination revealed plethoric appearance, conjunctiva: Congested .Pulse: 72b/ m BP: 130/80 mm of Hg, palmer erythema present. Systemic Examination revealed mild tenderness over epigastric region, mild splenomegaly. other systemic examinations were unremarkable.

His complete blood count revealed $\mathrm{Hb}-21.7 \mathrm{gm} / \mathrm{dl}$, WBC 16.42, RBC-10.63, Haematocrit - 65.8, MCV - 61.9, MCH 20.4, MCHC-33, Platelet- 369000 ,ESR- $18 \mathrm{~mm}$ in $1^{\text {st }}$ hour. Neutrophil - 70\%, Lymphocyte- 19.2\%, Monocyte$3.2 \%$,Eosinophil $-7.4 \%$, Basophil $-0.2 \%$. Unfortunately patient discarded all his previous enodoscopy images keeping only his papers. Review of his medical records showed duodenal ulcers in all his endoscopies but H. Pylori was absent in two of the three occasions. Even then he received eradication therapy.

His CXR was normal and echocardiography revealed no underlying heart disease. Persistently maintained oxygen saturation ( $\mathrm{SpO} 2)$ above $90 \%$ range ruled out secondary polycythemia indirectly as well. Due to inadequate facility in the ward, his oxygen saturation was measured in the OR where pulse oxymetry machine is available. 

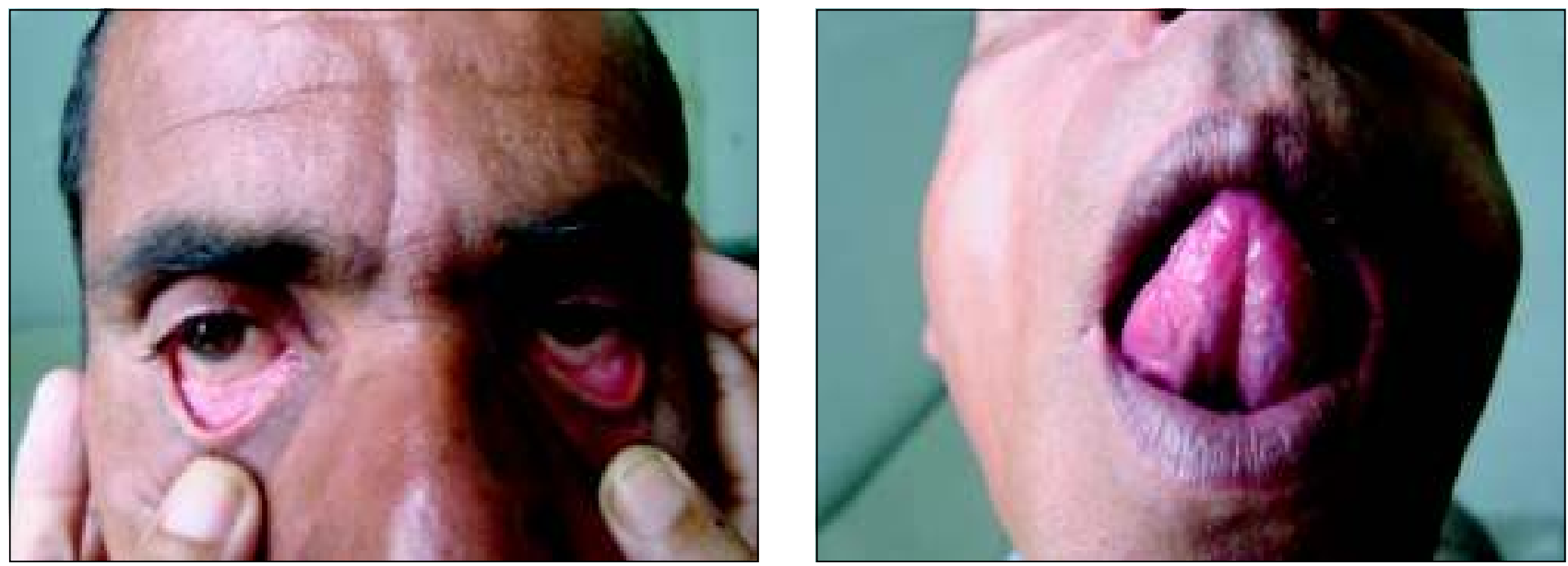

Fig.-1 Showing congested sclera and dorsum of the tongue.

\section{Discussion:}

While approaching a patient with abdominal pain in a medicine ward, one needs to be very cautious, especially while working in a setting where adequate investigation facilities are not present. There is no substitution for careful history taking and meticulous and thorough clinical examination. Although medial causes do not account for more than $5 \%$ of all abdominal pains, correct diagnosis is only reached by only those who are looking for a clue in all body systems, especially outside the abdomen. ${ }^{4}$

Diagnosis of polycythaemia vera is largely based on parameters set by polycythaemia study group ( $P V S G)$. It can be established if the following criteria are met $:^{5}$
But there are many controversies regarding these criteria. But the cornerstone of diagnosis is excluding the diagnosis of familial and secondary forms of polycythemia and thrombocytosis. Serum Epo assays are useful in the initial evaluation of erythrocytosis, particularly when related to simultaneous hemoglobin/ hematocrit determinations. Although PV remains a diagnostic possibility in the presence of low or normal serum Epo levels, erythrocytosis associated with increased Epo levels is usually due to secondary causes. Low Epo levels can also be seen in ET. Initial experience indicates that mutation screening for JAK2-V617F can accurately distinguish between PV and secondary polycythemias. $^{6-9}$

\section{CATEGORYA}

Lab Tests

A1: Total RBC Volume (REDMAS)

Male $>=36 \mathrm{ml} / \mathrm{kg} \mathrm{BW}$

Female $>=32 \mathrm{ml} / \mathrm{kg} \mathrm{BW}$

A2: Arterial saturation (OSAT)

$\mathrm{O} 2>92 \%$

A3: Splenomegaly (SPLEEN)

\section{CATEGORYB}

Lab Tests

B1: Thrombocytosis (WBC)

$>400,000 / \mathrm{mm} 3$

B2: Leukocytosis $>12,000 / \mathrm{mm} 3$ (PLAT)

(no fever or infection)

B3: Leukocyte alkaline phosphatase (LAP)

Score $>100$

B4a: Serum vitamin B12>900pg/ml or(B12)

B4b: Serum UB12BC >2,200 pg/ml(UBBC)

\section{DIAGNOSIS OFPOLYCYTHEMIAVERA:}

$\mathrm{A} 1+\mathrm{A} 2+\mathrm{A} 3$ or $\mathrm{A} 1+\mathrm{A} 2+$ any two from category $\mathrm{B}$ 
In our patient, many of the criteria of polycythaemia were fulfilled. Due to lack of diagnostic facility, we could not go for the complex laboratory testing. The interesting fact was patient fled the hospital when he was told about the treatment modalities, especially venesection probably out of fear.

But his mode of presentation makes this case unique and very interesting. Many medical conditions have been discussed as causative factor for abdominal pain in adults. They have been described under broad headings such as referred abdominal pain from heart such as myocarditis, endocarditis ,congestive heart failure, myocardial ischaemia and infarction. Respiratory causes such as pneumonia, pneumonitis, pulmonary, embolism and infarction can also cause abdominal pain.

Metabolic and endocrine causes such as ketoacidosis (diabetic and alcoholic), acute adrenal insufficiency, uraemia, hyperthyroidism, porphyria hyperparathyroidism/ hypercalcaemia, narcotic withdrawal. Even heat stroke, psychiatric disorders abdominal wall spasm/haematoma can cause abdominal pain. Many haematological cause such as sickle cell anaemia, haemolytic anaemia, Henoch-Schönlein purpura, acute leukaemia and polycythaemia rubra vera can also cause abdominal pain. ${ }^{10,11}$ various neurological causes and even toxins can cause cause abdominal pain.

Our patients recurrent abdominal pain led him to various physicians where medical cause was overlooked. The underlying mechanism for abdominal pain in polycythaemia has been attributed mostly to hyperviscosity syndrome but it has also been argued due to coagulopathies as well. ${ }^{4}$ It has been proved that qualitative platelet defect is present in polycythaemia contributed to various factors such as thrombocytosis, loss of VWF. ${ }^{12}$ Circulating, bone marrow hematopoietic stem cell-derived endothelial progenitors can home to areas of vascular injury or ischemia and repopulate the intimal surfaces of the vessel wall as differentiated endothelial cells. TPO and JAK2 mutations may also be responsible for increased platelet aggregation. The above mentioned factors might have been the underlying cause of the recurrent ulcers in our patient. ${ }^{13-15}$ Though the polycythaemia itself is not usually seen as an underlying cause of peptic ulceration or a common cause of abdominal pain, it must be kept in mind. This association is a rare finding and has not been reported earlier to the best of our knowledge.

It has been seen that the diagnostic accuracy of physicians assessing abdominal pain using clinical signs and symptoms and preliminary investigations is not very good. When preliminary and final diagnoses are compared, clinical accuracy has been reported to be $50-65 \%$ overall, and as low as $30 \%$ in the elderly. ${ }^{16,17}$ So, as physicians we must keep an open mind, and remain suspicious even when there is no reason to be so.

\section{Conflict of Interest: None}

\section{References:}

1. Colucciello SA, Lukens TW, Morgan DL. Assessing abdominal pain in adults: a rational, cost-effective, and evidence-based strategy. Emergency Medicine Practice 1999; $1: 1-20$

2. Kamin R, Nowicki TA, Courtney DS, Powers RD. Pearls and pitfalls in the emergency department evaluation of abdominal pain. Emerg Med Clin North Am 2003; 21:61-72

3. Gumina RJ, Foley DA, Tefferi A. Polycythemia vera-a case report and discussion on pathogenic mechanisms of increased thrombosis. Angiology 2002; 53:587-91

4. Farthing M J G. Pearls and pitfalls in the diagnosis of acute abdomen. Indian Journal of Gastroenterology. 2006; 25(Supplement 1):33-35

5. McMullin MF, Bareford D, Campbell P, et al On behalf of the General Haematology Task Force of the British Committee for Standards in Haematology. Guidelines for the diagnosis, investigation and management of polycythaemia/erythrocytosis. Br J Haematol. 2005; 130:174-195

6. Tefferi A. Polycythemia vera: a comprehensive review and clinical recommendations. Mayo Clin Proc. 2003;78: 174-194

7. Sirhan S, Fairbanks VF, Tefferi A. Red cell mass and plasma volume measurements in polycythemia. Evaluation of performance and practical utility. Cancer. 2005; 104: 213-215

8. Mossuz P, Girodon F, Donnard M, et al. Diagnostic value of serum erythropoietin level in patients with absolute erythrocytosis. Haematologica. 2004;89: 1194-1198

9. Tefferi A, Sirhan S, Lasho TL, et al. Concomitant neutrophil JAK2 mutation screening and PRV-1 expression analysis in myeloproliferative disorders and secondary polycythaemia. Br J Haematol. 2005; 131:166-171

10. King KE, Wightman JM. Abdominal pain. In: Marx JA, editor. Rosen's emergency medicine: concepts and clinical practice. 6th edn. Philadelphia: Mosby Elsevier, 2006; 209-18

11. Fishman M, Aronson M. Differential diagnosis of abdominal pain in adults UpToDate 2008;16.1. Available at www.uptodate.com/patients/content/topic. do?topicKey= $\sim 9 F T C 32 \mathrm{rdzms} / \mathrm{x} 9$ 
JM Vol. 13, No. 2

12. Schafer A I. Molecular basis of the diagnosis and treatment of polycythemia vera and essential thrombocythemia. Blood. 2006; 107: 4214-4222

13. Schatterman GC. Adult bone marrow-derived hemangioblasts, endothelial cell progenitors, and EPCs. Curr Top Dev Biol. 2004; 64:141-180

14. Urbich C, Dimmeler S. Endothelial progenitor cells. Characterization and role in vascular biology. Circ Res. 2004; 95:343-353
Polycythaemia Vera with Abdominal Pain - An Unusual Association

15. Kubota Y, Tanaka T, Ohnishi H, et al. Constitutively activated phosphatidylinositol-3-kinase primes platelets from patients with chronic myelogenous leukemia for thrombopoietininduced aggregation. Leukemia. 2004; 18:1127-1137

16. Gallaher EJ. Acute abdominal pain. In: Tintinalli JE, Kelen GD, Stapczynski JS, editors. Emergency medicine: a comprehensive study guide. 6th edn. New York: McGrawHill Companies, 2004; 487-501

17. Graff LG, Robinson D. Abdominal pain and emergency department evaluation. Emerg Med Clin North Am 2001; 19:123-36 